\title{
Factors in Patient Empowerment: A Survey of an Online Patient Research Network
}

\author{
Emil Chiauzzi $^{1} \cdot$ Pronabesh DasMahapatra $^{1} \cdot$ Elisenda Cochin $^{1} \cdot$ Mikele Bunce $^{2}$. \\ Raya Khoury $^{2} \cdot$ Purav Dave $^{2}$
}

Published online: 7 May 2016

(c) The Author(s) 2016. This article is published with open access at Springerlink.com

\begin{abstract}
Background Providers and healthcare organizations have begun recognizing the importance of patient empowerment as a driver of patient-centered care. Unfortunately, most studies have investigated empowerment with single diseases. Identifying factors of empowerment across conditions and populations would enable a greater understanding of this construct.

Objective The purpose of this study was to understand empowerment in relation to health information-seeking, interactions with providers and peers, and healthcare access in chronic disease patients. This study also sought to identify key empowerment factors and their association with patient characteristics.
\end{abstract}

Electronic supplementary material The online version of this article (doi:10.1007/s40271-016-0171-2) contains supplementary material, which is available to authorized users.

Emil Chiauzzi

echiauzzi@patientslikeme.com

Pronabesh DasMahapatra

pdasmahapatra@patientslikeme.com

Elisenda Cochin

ecochin@patientslikeme.com

Mikele Bunce

bunce.mikele@gene.com

Raya Khoury

khouryr1@gene.com

Purav Dave

dave.purav@gene.com

1 PatientsLikeMe, Inc., 160 Second Street, Cambridge, MA 02142, USA

2 Genenetech, South San Francisco, CA, USA
Methods Participants were recruited through PatientsLikeMe, an online research platform where patients share their personal and medical history data. Patients completed an online survey that assessed self-reported health behavior (e.g. knowledge-seeking, experiences with healthcare providers, and peer interactions) and healthcare access. An exploratory factor analysis identified key empowerment domains. Domain level sum scores and sum of all domains (total score) were compared across patient characteristics and diseases.

Results Overall, 3988 participants were included in the study, with the majority actively involved in their healthcare, but many cited difficulties with matching their treatment goals with those of their physician (34\%) and spending sufficient time with the physician (36\%). Factor analysis identified two domains-Positive Patient-Provider Interaction, and Knowledge and Personal Controlthat explained $>60 \%$ of the overall variance in the observed variables. Mean total empowerment scores for patients with a primary complaint of Parkinson's disease (61.8) and multiple sclerosis (60.3) were significantly greater than fibromyalgia (55.3) and chronic fatigue syndrome (54.8). Patients who were older, male, more educated, and insured also reported significantly greater levels of empowerment.

Conclusions The two domains of empowerment identified in this study are consistent with previous studies, but the differences in empowerment levels across diseases suggest a need for further studies on disease-related attributes of empowerment. Future research should examine the pathways for empowerment, as well as the relationship between empowerment domains and clinical outcomes. 


\section{Key Points for Decision Makers}

Clinicians: Greater attention needs to be paid to helping clinicians provide sufficient time to develop mutually acceptable treatment goals with patients, as well as attend to informational needs in difficult-totreat conditions.

Patients: Educating patients about the importance of seeking support to improve knowledge and a sense of control may enhance empowerment, particularly in difficult-to-manage chronic conditions.

Researchers: Interpersonal and intrapersonal factors in empowerment have been identified but further research is needed to examine causal relationships among key constructs.

\section{Background}

Patients with chronic diseases are faced with a broad array of treatment options that require healthcare knowledge, the ability to navigate services and providers, and a proactive approach to self-care [1]. These challenges are especially magnified in patients who have differential access to care based on healthcare insurance, education, and income [2]. To address these needs, providers and healthcare organizations have begun recognizing the importance of involving patients more proactively in their treatment. The Institute of Medicine highlighted the importance of the patient as "the source of control" in medical care [3]. The emergence of the Patient-Centered Outcomes Research Institute (PCORI) [4] and Food and Drug Administration (FDA) Patient-Focused Drug Development Initiative [5] have led to important patient-centered initiatives. The PCORI has involved underserved patients in the development and implementation of comparative effectiveness studies. As a means of informing regulatory decisions, the FDA is conducting meetings to capture the 'patient voice' in conditions such as fibromyalgia and lung cancer. The importance of engaging patients in their care has been magnified by findings suggesting that patients with the skills and confidence to manage their health achieve better health outcomes and help drive lower costs [1]. To advance these aims, the National Quality Strategy has emphasized that patients and their families engage as partners in their care [6].

These trends have helped give rise to an emphasis on patient empowerment as a driver of patient-centered care
[7]. Recent reviews have found that empowerment is not disease-specific and can be regarded as a psychosocial skill, a result of experiential learning, and a determinant of a reciprocal relationship with provider(s) [8]. Johnson [9] and Small et al. [10] have proposed models of empowerment that suggest the primacy of interpersonal and intrapersonal factors. Johnson's Model of Health Care Empowerment suggests an interplay of personal resources (e.g. problem solving, communication, healthcare access), cultural/social/environmental factors (e.g. perceived norms, stigma, trauma), and intrapersonal factors (e.g. depression, hope), which ultimately influence healthcare empowerment (e.g. engagement, collaboration) [9]. Small et al. [10] conducted a postal validation study of an empowerment measure with an elderly group of women with chronic diseases recruited from general practices. A qualitative study identified five dimensions (identity, knowledge and understanding, personal control, personal decision making, and enabling other patients) but these were not confirmed in a survey conducted to validate the new novel empowerment measure. A three-factor solution included 'positive attitude and sense of control' and 'knowledge and confidence in decision making', but the third factor was comprised of a mixture of items and could not be clearly identified. The authors concluded that the lack of clarity in these results required further testing and that scoring be restricted to a total score.

Identifying factors of patient empowerment is particularly important for achieving better outcomes with patients who have chronic conditions [10]. Higher levels of empowerment are associated with fewer symptoms [11]. Active participation in healthcare is associated with greater perceived confidence in treatment adherence and with selfreports of recent medication adherence [12]. Another line of research has evaluated the efficacy of face-to-face, group, or Internet-based educational programs to promote patient empowerment in decision making or provider interactions [13]. Unfortunately, most studies have investigated empowerment as a construct with single diseases $[12,14]$. It would be useful to identify factors of empowerment broadly across conditions and populations.

The purpose of this study was to understand empowerment in terms of how chronic-disease patients in an online community engage in health information seeking, interactions with providers and peers, and healthcare access. In addition, this study sought to identify key factors in empowerment and their association with patient characteristics. Ultimately, such analyses may inform actionable steps that both patients and providers can take in order to encourage and improve patient empowerment. 


\section{Methods}

\subsection{Participants and Procedures}

Patients were recruited through PatientsLikeMe (PLM; http://www.patientslikeme.com), an online research platform that allows patients to share personal health information through structured data collection [15]. At present, PLM has over 430,000 members representing over 2600 conditions. PLM members self-report demographic, diagnosis, medical history, treatment, and symptom data. Due to the availability of a large, multiple-disease patient cohort in an online research network, PLM is able to quickly and efficiently recruit participants in surveys. In recent years, the use of online surveys has multiplied due to the reduced burden on participants, cost effectiveness, and automation of data collection and tracking when compared with mail surveys [16]. However, because of self-selection in online populations, the sample constitution may differ from representative population-based samples [17]. The advantages of online survey administration on PLM have been documented in previous studies [18].

The inclusion criteria were registration on the PLM website, one or more chronic health condition(s) on the PLM profile, and age $\geq 18$ years. In the survey sample, we included conditions that were reported by more than five patients. Members were not remunerated for their participation. Invitations were sent via electronic message to an unrestricted convenience sample of PLM members. Participation in the survey was voluntary, and the nature and potential risks of the study were explained. Informed consent was obtained electronically before commencing the survey. The research protocol was approved by the New England Institutional Review Board (NEIRB) on 4 November 2014, and the online survey was administered to members of the PLM website between 10 and 26 November 2014.

\subsection{Measures}

\subsubsection{Profile Data}

Variables included in the analyses were age, gender, race, residence, health insurance, education, primary condition (i.e. a member's chief complaint) and other comorbidities, which patients report in their PLM profile.

\subsubsection{Empowerment Survey}

The creation of the survey began with a review of published studies to identify concepts and domains of empowerment. A detailed review of the articles identified a theoretical framework of patient empowerment in chronic disease that helped inform development of survey items [10]. A list of questions was generated from the concepts identified in the studies and was subjected to an iterative process of development and selection by the authors. Skiplogic (also known as conditional branching), an interactive feature that allows respondents to skip questions not applicable to them based on prior responses, was then embedded within the survey to improve usability. Development and pretesting (comprehensibility and functionality of the electronic questionnaire) were carried out iteratively by the team of research investigators. The survey was then reviewed for editorial and technical suggestions by patient community moderators at PLM. This stepwise process fulfilled the criteria outlined in the Checklist for Reporting Results of Internet E-Surveys (CHERRIES) [17]. For supplemental analyses, survey data were combined with profile data from PLM member accounts.

The final survey included 47 questions covering demographic items not included in the PLM profile (e.g. employment and marital status), self-reported health behavior (knowledge seeking, patient-provider interactions, and peer interactions), and healthcare access. Response options varied by the type of questions, and ranged from numerical, categorical (multiple choicemutually exclusive or inclusive and exhaustive), ordinal (Likert scale), to open-ended comments. Response options for empowerment domain items were set to a 5-point Likert rating scale (ordinal scale ranging from least to most desirable in order to have sufficient variability to uncover latent structure of factor models). Survey responses were collected using the online research survey tool developed by PLM and stored in a secure database. A copy of the survey, as fielded to participants, has been added as Online Resource 1.

\subsection{Data Analysis}

Analyses were conducted in patients who completed the entire survey. Individuals who terminated the survey early were excluded and no imputation was performed for missing data. Duplicate entries were also removed from analyses. Data analyses were performed in SAS version 9.4 (SAS Institute Inc., Cary, NC, USA), and the level of significance was set at $\alpha=0.05$. Given the large sampling frame, a priori power estimation was not performed. Data analyses were conducted using the following steps:

\subsubsection{Descriptive Analysis}

Descriptive statistics were computed for demographic variables and survey items, and were presented as mean 
[standard deviation (SD)] for continuous variables (median, interquartile range for non-normally distributed variables) and frequency (\%) for categorical variables. Differences in demographic distribution between completers and non-completers were tested using the $t$ test for continuous variables (Wilcoxon test for non-normal data) and the Chi-square test for categorical variables.

\subsubsection{Exploratory Factor Analysis}

2.3.2.1 Factor Solution Summary statistics of the empowerment questions at the item level were computed as means, SDs and percentages for all Likert scale rating items (range 1-5). To explore dimensionality of the questions and the number of distinct common factors measuring the underlying construct of empowerment, exploratory factor analysis (EFA) was performed for 26 candidate items. Optimum factor solution was identified by examining (i) eigenvalues $(>1)$; (ii) scree plot; and (iii) factor loadings $(\geq 0.4)$ and cross-loadings. Principal axis factoring followed by promax rotation was run on the final factor solution following item reduction (i.e. removing items with factor loading $<0.4)$. Finally, Cronbach's $\alpha$ was computed for each factor to measure the scale reliability (internal consistency), and item-to-total correlations and item-level discriminant validity of each item in relation to the underlying factor were computed. The sum score of all items in the common factor(s) identified by EFA were used as composite measures for each domain. While exploratory, the composite scale metric has several advantages. Mean scores may be useful for comparisons across factors when there are differing numbers of items per factor. Summed factor scores preserve the variation in the original data and is a common approach in exploratory research studies [18]. The domains identified from the final EFA solution were then assigned nomenclature that explained the items contained in the domain. For subsequent analyses, domain level scores were used as measures of domains of empowerment, and the sum of all retained items were used as the total empowerment score. Furthermore, items that were retained from the EFA were examined by tabulating the percentage of positive responses (rating of 4 or 5 on the 5-point Likert items) across the most prevalent primary conditions.

\subsubsection{Subgroup Analysis using Factor Scores Mean} factor scores were examined across different strata of the study population. The stratifying variables were age, gender (male vs. female), education (high school or less vs. attended college vs. advanced degree), health insurance status (yes vs. no), work status (able to work vs. medically disabled to work), and primary condition. Ninety-five percent confidence intervals (CIs) were computed around the means where appropriate. For comparing scores across primary conditions with the design-based weighted mean of the overall sample, the analysis of means (ANOM) procedure was selected. ANOM is a multiple comparison procedure that constructs simultaneous critical values and CIs to contrast subgroups with the overall weighted mean, while controlling the type I error rate. Decision limits were plotted to statistically and visually test the hypothesis of differences in condition-specific means with the overall weighted mean after Nelson-Hsu multiplicity adjustment.

\section{Results}

\subsection{Descriptive Analysis Results}

\subsubsection{Survey Participation}

PLM members $(n=294,795)$ were invited to participate in the survey. Of these members, 21,923 viewed the invitation and 6872 patients electronically consented to participate in the survey; 15,501 did not respond or opted out. Among consented patients, 1535 were excluded box (duplicates $=3$, asked to be removed after consent $\mathrm{n}=1$, and did not meet eligibility criteria $=1531$ ). Of the remaining 5337 participants, 3988 completed the survey; 1349 abandoned the survey after starting.

\subsubsection{Response Rate}

The view rate (views/invites), participation rate (participants/ views) and completion rate (completers/participants) were 7 , 24 , and $75 \%$, respectively. The completion rate was higher (75 vs. $60 \%$ ) than Internet surveys of similar length [19]. Figure 1 represents the flow of participants through the study. Eligible participants who completed the survey $(n=3988)$ were included in the final analyses sample.

Using available data (all participants may not have complete demographic data), comparisons of completers and non-completers indicated that the former were slightly older than the latter (mean 52.5 vs. 51.2 years, $t=3.2$, $p=0.001)$ and completers reported more chronic conditions on their PLM profile (median 2 vs. $1, z=10.4$, $p<0.0001$ ). Of note, completers were more likely to be White, more educated, medically unable to work, have health insurance, and reside in the US (see Table 1).

\subsubsection{Demographic and Disease Characteristics}

The mean age of the study sample at the time of the survey was 52.5 years (SD 12 years), with a median of two selfreported conditions listed on their PLM profile (interquartile range 1-4). The majority of participants were females 


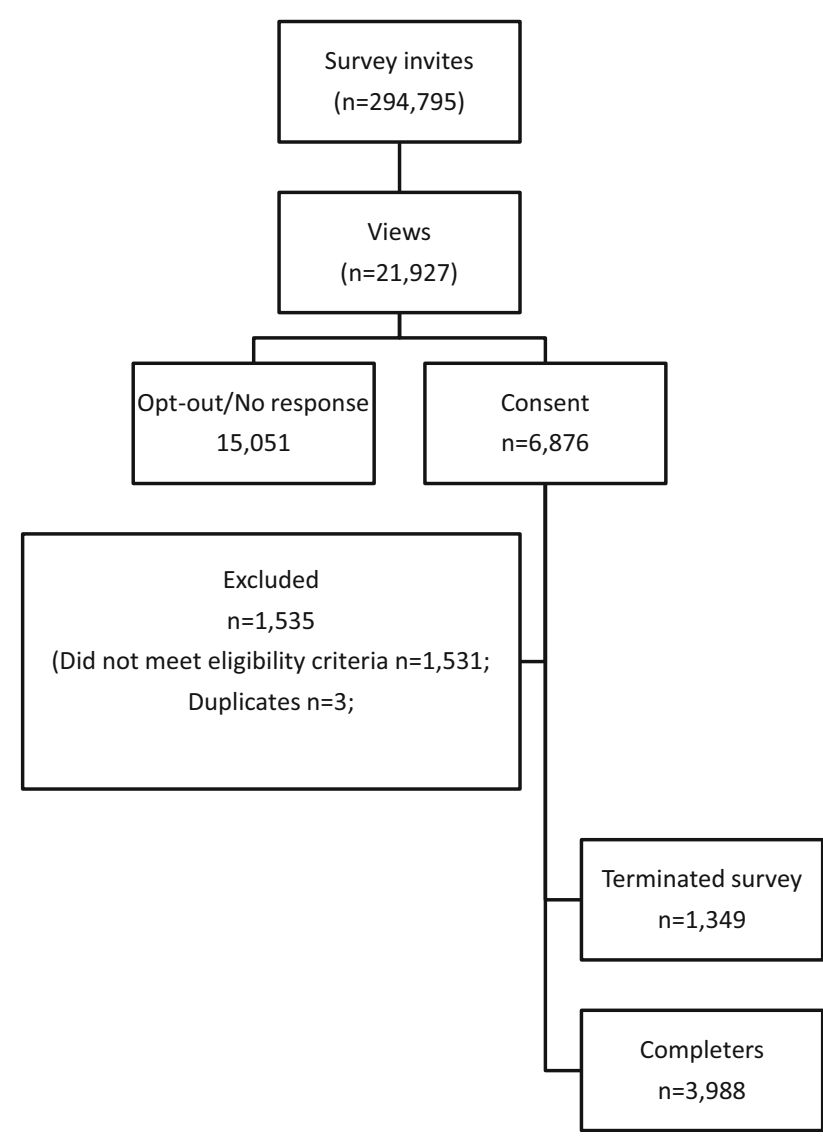

Fig. 1 Study participation process. Overall, 21,923 participants viewed the invitation, of whom 6872 patients electronically consented to participate in the survey; 15,051 did not respond or opted out. Among consented patients, 1535 were excluded box (duplicates $=3$, asked to be removed after consent $n=1$, did not meet the eligibility criteria $=1531$ ). Of the remaining 5337 participants, 3988 completed the survey; 1349 abandoned the survey after starting. The view rate (views/invites), participation rate (participants/views), and completion rate (completers/participants) were 7,24 , and $75 \%$, respectively

(72\%, $n=2883)$, White $(90 \%, n=3594)$, and attended college $(82 \%, n=3279)$. Most participants had health insurance $(90 \%, n=3602)$ but more than one-third of patients $(37 \%, n=1464)$ were medically unable to work. The most prevalent primary conditions were fibromyalgia (20\%, $n=814)$, multiple sclerosis $(19 \%, n=766)$, and Parkinson's Disease $(8 \%, n=319)$. More than threequarters ( $77 \%, n=3094$ ) of patients were affected 'often' to 'always' in their activities of daily living due to their condition. Participants reported high levels of prediagnosis healthcare involvement, with $87 \%(n=3504)$ citing that it was somewhat or very important to them to be involved in making decisions about their health prior to diagnosis (see Table 1 for more information).

Compared with the US Department of Health and Human Services statistics on chronic disease populations, our study sample underrepresents the most prevalent chronic conditions (e.g. cardiometabolic and respiratory diseases), ethnic minorities and older patients, and overrepresents debilitating neurological and movement disorders (fibromyalgia, multiple sclerosis, Parkinson's disease), females, and more educated and insured participants [20]. The proportion of females in this sample may be partially explained by the gender distribution of fibromyalgia (80-90\% females) [21] and multiple sclerosis (as high as $3: 1$ to $4: 1$ females) [22]. Finally, multiple sclerosis and Parkinson's disease are less common in minority populations [22, 23].

\subsubsection{Health Information Seeking and Interactions}

Our study sample generally reported positive indicators of health education, as well as positive interactions with providers and peers. Knowledge-seeking behavior was reported to be high, with resources such as health websites (WebMD, MayoClinic, etc.), patientslikeme.com, books, magazines, and journals cited by $87 \%(n=3489), 60 \%$ $(n=2411), 43 \%(n=1734), 40 \%(n=1598)$, and $36 \%$ ( $n=1431)$ of patients, respectively, as sources they use to learn about their condition. Patients sought educational resources for a variety of reasons, including (in descending order) learning about treatment options $(83 \%, n=3315)$, course and progression of disease $(76 \%, n=3050)$, signs and symptoms ( $68 \%, n=2720)$, cause of condition (51\%, $n=2029)$, initial diagnosis $(50 \%, n=2001)$, and health monitoring ( $48 \%, n=1926)$. The majority of patients assessed health information verbally from providers (59\%, $n=2359)$, and many of them also accessed paper copies $(43 \%, n=1714)$ and patient portals $(43 \%, n=1711)$.

\subsubsection{Interactions with Health Providers and Peers}

Most patients reported positive impressions of their health interactions with their providers and peers. Sixty-four percent $(n=2633)$ agreed that they were content with access to healthcare services and approximately threequarters $(73 \%, n=2883)$ were satisfied with continued care from their provider and healthcare institution $(73 \%$, $n=2879)$. Seventy-seven percent $(n=3061)$ were satisfied with their primary provider relationship, the majority of patients ( $79 \%, n=3147)$ agreed that they have a say in treatment decision making, and $73 \%(n=2888)$ reported satisfaction with the continued care from their provider. Despite these positive reactions, a sizable minority of patients did not feel that their treatment goals matched their providers' plan $(34 \%, n=1251)$ or that they spent an adequate amount of time with their main provider during visits $(36 \%, n=1426)$. In addition, the percentage of positive responses (4 or 5 on the 5-point Likert scale) across primary conditions was lowest for the following two survey questions: (1) to what extent do you feel your main 
Table 1 Demographic characteristics of the study population

\begin{tabular}{|c|c|c|c|c|}
\hline & $\begin{array}{l}\text { Completers } \\
(n=3988)\end{array}$ & $\begin{array}{l}\text { Non-completers } \\
(n=1349)\end{array}$ & $\begin{array}{l}\text { Test } \\
\text { statistic }^{\mathrm{a}}\end{array}$ & $p$ value \\
\hline Age [years; mean $\pm \mathrm{SD}]$ & $52.5 \pm 12.2$ & $51.2 \pm 12.8$ & 3.2 & 0.001 \\
\hline Number of self-reported conditions [median (IQR)] & $2(1-4)$ & $1(1-2)$ & 10.4 & $<0.0001$ \\
\hline Gender $[\%(n)]$ & & & 0.1 & 0.706 \\
\hline Female & $72(2883)$ & $65(882)$ & & \\
\hline Male & $28(1094)$ & $26(344)$ & & \\
\hline Unreported & $<1(11)$ & $9(123)$ & & \\
\hline Race $[\%(n)]$ & & & 9.2 & 0.002 \\
\hline White & $90(3594)$ & $79(1071)$ & & \\
\hline Non-White & $8(321)$ & $10(133)$ & & \\
\hline Unreported & $2(73)$ & $11(145)$ & & \\
\hline Education $[\%(n)]$ & & & 6.8 & 0.033 \\
\hline Less than college & $16(638)$ & $16(212)$ & & \\
\hline Attended college & $62(2462)$ & $52(701)$ & & \\
\hline Advanced degree & $20(817)$ & $15(203)$ & & \\
\hline Unreported & $2(71)$ & $17(233)$ & & \\
\hline Health Insurance $[\%(n)]$ & & & 12.7 & $<0.001$ \\
\hline Yes & $90(3602)$ & $72(974)$ & & \\
\hline No & $7(267)$ & $8(110)$ & & \\
\hline Unreported & $3(119)$ & $20(265)$ & & \\
\hline Work status $[\%(n)]$ & & & 13.1 & $<0.001$ \\
\hline Medically unable to work & $37(1464)$ & $26(356)$ & & \\
\hline Able to work & $61(2423)$ & $57(765)$ & & \\
\hline Unreported & $2(101)$ & $17(228)$ & & \\
\hline Region $[\%(n)]$ & & & 13.1 & 0.004 \\
\hline US & $69(2744)$ & $60(810)$ & & \\
\hline UK & $13(534)$ & $14(193)$ & & \\
\hline Canada & $8(323)$ & $6(79)$ & & \\
\hline Other & $9(379)$ & $11(145)$ & & \\
\hline Unreported & $<1(8)$ & $9(122)$ & & \\
\hline Primary condition $[\%(n)]$ & & & 108.7 & 0.018 \\
\hline Fibromyalgia & $20(814)$ & $22(301)$ & & \\
\hline Multiple sclerosis & $19(766)$ & $16(213)$ & & \\
\hline Parkinson's disease & $8(319)$ & $7(89)$ & & \\
\hline Type 2 diabetes mellitus & $5(193)$ & $6(76)$ & & \\
\hline Epilepsy & $4(165)$ & $3(37)$ & & \\
\hline Amyotrophic lateral sclerosis & $3(110)$ & $4(48)$ & & \\
\hline Rheumatoid arthritis & $3(123)$ & $2(33)$ & & \\
\hline Systemic lupus erythematosus & $3(100)$ & $2(33)$ & & \\
\hline Major depressive disorder & $2(95)$ & $2(33)$ & & \\
\hline Idiopathic pulmonary fibrosis & $2(90)$ & $2(27)$ & & \\
\hline Myalgic encephalomyelitis/chronic fatigue syndrome & $2(76)$ & $3(45)$ & & \\
\hline Migraine & $2(64)$ & $2(25)$ & & \\
\hline Bipolar disorder type 2 & $1(55)$ & $1(17)$ & & \\
\hline Other & $24(979)$ & $29(398)$ & & \\
\hline Interference in activities of daily living (often-always) [\%(n)] & $78(3094)$ & - & & \\
\hline $\begin{array}{l}\text { Prediagnosis healthcare involvement (important-very important) } \\
{[\%(n)]}\end{array}$ & $87(3504)$ & - & & \\
\hline
\end{tabular}

$S D$ standard deviation, $I Q R$ interquartile range

${ }^{\text {a }}$ Test statistics for the difference between completers and non-completers were computed using available profile data only (excluding unreported). The test statistic is $t$ test for age, Wilcoxon two-sample $z$ test for condition count (non-normal distribution), and Chi-square test for categorical data. Multiplicity adjustments were not performed 
healthcare provider monitors your ongoing care (a great deal or quite a bit; $55 \%$ across all conditions); and (2) I have as much support as I need from friends to help care for and manage my condition (strongly agree or agree; $47 \%$ across all conditions).

Peer interactions were also noted among patients, with $74 \%(n=2943)$ citing enabling other patients ("I have shared my experience of managing my condition with other people") and $69 \%(n=2739)$ learning from others ("Do you learn from the experiences of other members that are part of online communities like PatientsLikeMe?").

\subsection{Exploratory Factor Analysis}

We assessed 26 survey items (see Online Resource 2) using EFA to examine common factors that measure the underlying construct of empowerment. Due to the non-normal distribution of data, we applied the principal axis factoring method, which is robust for non-normal data distributions. Sampling adequacy for EFA measured by Kaiser-MeyerOlkin $(\mathrm{KMO})$ revealed adequate sample size $(\mathrm{KMO}=0.9)$. The optimum EFA solution had two factors with eigenvalues of 5.7 and 1.3 for the first and second factors, respectively, accounting for $>60 \%$ of the overall variance in the observed variables. Sixteen $(n=16)$ items loaded $>0.4$ on one of the two factors, with a few items loading on more than one factor (cross-loading) (Table 2; see Appendix 2 for all 26 items). Discriminant validity of the 16 items assessed by corrected item-to-total correlation (correlations between items and total domain score with the item excluded in the domain total) [24] showed one item on the second factor had poor discriminant validity $(<0.4)$ and was removed. The final factor solution contained eight items on the first factor and seven on the second factor. After reviewing the items contained within each factor (domain), the factors were named according to what the common theme of items within each factor best represented, i.e. 'Positive Patient-Provider Interaction' and 'Knowledge and Personal Control'. Internal consistency testing of the factors demonstrated acceptable Cronbach's $\alpha$ for each domain $(\alpha>0.79)$. The factor scores were used as composite measures of each domain and the sum of both factor scores was used as the 'Total Empowerment Score'. A higher score indicates greater empowerment for Positive Patient-Provider Interaction (minimum 8, maximum 40), Knowledge and Personal Control (minimum 7, maximum 35), and Total Empowerment Score (minimum 15, maximum 75) domains.

\subsubsection{Patient Empowerment and Patient Characteristics}

Positive Patient-Provider Interaction scores varied by patient characteristics, including primary condition, age, gender, insurance status, and education. Mean scores were higher in males (males 32.5 vs. females 31.6), more educated (advanced education 32.7 vs. college 31.9 vs. high school or less 30.8), and older (with the exception of age category $>75$ years) patients, and lower in uninsured patients (uninsured 28.2 vs. insured 32.1) (Table 3). No significant difference was noted in the scores of patients by work status (medically unable to work vs. able to work). Furthermore, patients with myalgic encephalomyelitis/ chronic fatigue syndrome (28.6), systemic lupus erythematosus (29.4), and fibromyalgia (29.7) reported significantly lower scores compared with the overall weighted mean (Fig. 2). Patients with neurological disorders, including Parkinson's disease (33.5) and multiple sclerosis (33.1), reported significantly higher scores compared with the overall weighted mean.

There were two particular items in this scale that revealed specific differences by conditions. In patients with amyotrophic lateral sclerosis, $86 \%$ responded that they strongly agree or agree (compared with $73 \%$ across all diseases) to the survey item: "I am well-informed about the available treatment options for my primary health condition". For the same item, patients with Parkinson's disease and multiple sclerosis also had a high percentage of agreement (84 and $85 \%$, respectively); however, the percentage agreement for patients with fibromyalgia $(58 \%)$ and chronic fatigue syndrome (59\%) was less for the same survey item (see Online Resource 3). Compared with the overall sample, a smaller percentage of fibromyalgia (63\%) and chronic fatigue syndrome $(64 \%)$ respondents positively endorsed "How much of the health information you received from healthcare providers during your visits was clear and easy to understand".

Knowledge and Personal Control scores were higher in males (males 27.8 vs. females 26.4), more educated (advanced education 27.7 vs. college 26.6 vs. high school or less 26.2), and older patients, and lower in those uninsured (uninsured 24.9 vs. insured 26.9) and patients who were medically unable to work (medically unable to work 26.2 vs. able to work 27.1) (Table 3). Patients with major depressive disorder (24.5), myalgic encephalomyelitis/ chronic fatigue syndrome (24.7), and fibromyalgia (24.8) reported significantly lower scores compared with the weighted sample mean (Fig. 2), while patients with neurological disorders, including amyotrophic lateral sclerosis (28.4), Parkinson's disease (28.0), and multiple sclerosis (27.8) reported higher scores than overall weighted mean. As expected, Total Empowerment scores also differed by sociodemographic and primary conditions (Table 3).

\subsubsection{Patient Empowerment and Healthcare Access}

Satisfaction with healthcare access (sum score of a nineitem unidimensional construct) was also strongly 
Table 2 Exploratory factor analysis and internal consistency of the empowerment items ${ }^{\mathrm{a}}$

\begin{tabular}{|c|c|c|}
\hline Items/questions & $\begin{array}{l}\text { Positive Patient-Provider Interaction } \\
\text { (Factor 1) (Cronbach's } \alpha=0.89 \text { ) }\end{array}$ & $\begin{array}{l}\text { Knowledge and Personal Control } \\
\text { (Factor 2) (Cronbach's } \alpha=0.79 \text { ) }\end{array}$ \\
\hline $\begin{array}{l}\text { How satisfied are you with the relationship you have with the } \\
\text { healthcare provider who treats your primary condition? }\end{array}$ & $\mathbf{0 . 8 8}$ & \\
\hline $\begin{array}{l}\text { Are you satisfied with the follow-up care you receive from the } \\
\text { healthcare provider who treats your primary condition? }\end{array}$ & 0.87 & \\
\hline $\begin{array}{l}\text { How much trust do you have in the competence of the healthcare } \\
\text { provider who treats your primary condition? }\end{array}$ & $\mathbf{0 . 8 2}$ & \\
\hline $\begin{array}{l}\text { To what extent do you feel your main healthcare provider monitors } \\
\text { your ongoing care? }\end{array}$ & $\mathbf{0 . 7 3}$ & \\
\hline $\begin{array}{l}\text { How much do your treatment goals match with your healthcare } \\
\text { providers' treatment plan? }\end{array}$ & 0.71 & 0.47 \\
\hline $\begin{array}{l}\text { How much of the health information you received from healthcare } \\
\text { providers during your visits was clear and easy to understand? }\end{array}$ & $\mathbf{0 . 5 0}$ & 0.45 \\
\hline $\begin{array}{l}\text { How much say do you think you have in making decisions about } \\
\text { your treatment? }\end{array}$ & 0.49 & 0.44 \\
\hline $\begin{array}{l}\text { How much of the information that you receive in the educational } \\
\text { materials during your visits is clear and easy to understand? }\end{array}$ & 0.47 & 0.42 \\
\hline $\begin{array}{l}\text { I am aware of the warning signs/symptoms related to my primary } \\
\text { health condition }\end{array}$ & & 0.74 \\
\hline $\begin{array}{l}\text { I feel confident in managing any warning signs/symptoms of my } \\
\text { primary health condition }\end{array}$ & & 0.75 \\
\hline $\begin{array}{l}\text { I am well-informed about the available treatment options for my } \\
\text { primary health condition }\end{array}$ & 0.49 & 0.72 \\
\hline I know how my primary condition progresses over time & & 0.61 \\
\hline $\begin{array}{l}\text { I have as much support as I need from friends to help care for and } \\
\text { manage my condition }\end{array}$ & & 0.48 \\
\hline $\begin{array}{l}\text { Of the educational information you read about health, how much of } \\
\text { it is clear and easy to understand? }\end{array}$ & & 0.40 \\
\hline $\begin{array}{l}\text { I have as much family support I need to help care for and manage } \\
\text { my condition }\end{array}$ & & 0.44 \\
\hline $\begin{array}{l}\text { Of the health information about test results and medical reports you } \\
\text { receive, how much of it is clear and easy to understand? }\end{array}$ & 0.45 & $\mathbf{0 . 5 0}$ \\
\hline
\end{tabular}

Bold numbers represent loadings of items 1-8 on Factor 1, and items 9-16 on Factor 2. Psychometric testing of factors demonstrated acceptable Cronbach's $\alpha$ for each subscale $(\alpha>0.79)$

${ }^{a}$ EFA identified two components; principal axis factoring followed by promax rotation was run using the two-factor solution. Sixteen $(n=16)$ items loaded $>0.4$

${ }^{\mathrm{b}}$ Item 14 (in italics) was removed due to poor discriminant validity, as measured by corrected item-to-total correlation (correlations between items and total domain score with the item excluded in the domain total; not shown in the table)

correlated with empowerment scores (Total Empowerment Scorer $=0.7, \quad p<0.0001 ; \quad$ Positive Patient-Provider Interaction, $r=0.7, p<0.0001$; Knowledge and Personal Control, $r=0.6, p<0.0001$; not shown in the tables).

\section{Discussion}

The goal of the present study was to gain an understanding of empowerment in terms of how chronic disease patients participating in an online community engage in health information seeking, interact with providers and peers, and access healthcare. The analysis of the sample as a whole revealed a fairly engaged and empowered group, but many experience disconnects in the delivery of care (e.g. inadequacies in treatment goal setting and time spent in visits). This study sought to identify key factors in empowerment and their association with patient characteristics. Two important components of empowerment-positive patientprovider interactions and knowledge and personal control-were identified. Levels of these empowerment factors varied across disease type.

\subsection{Descriptive Findings}

Patients were actively involved in information seeking, and generally reported satisfaction with access to and provision of care, and high levels of prediagnosis involvement in 
Table 3 Mean empowerment scores (total and factor level) with $95 \%$ CIs across sociodemographic strata

\begin{tabular}{|c|c|c|c|}
\hline & $\begin{array}{l}\text { Positive Patient-Provider Interaction } \\
\text { Score [mean }(95 \% \mathrm{CI})]\end{array}$ & $\begin{array}{l}\text { Knowledge and Personal Control } \\
\text { Score }[\text { mean }(95 \% \mathrm{CI})]\end{array}$ & $\begin{array}{l}\text { Total Empowerment Score } \\
{[\text { mean }(95 \% \mathrm{CI})]}\end{array}$ \\
\hline \multicolumn{4}{|l|}{ Age categories, years } \\
\hline 18-34 Gen Y & $30.2(29.4-30.9)$ & $25.7(25.1-26.2)$ & $56.5(55.3-57.7)$ \\
\hline 35-44 Gen X & $30.2(29.6-30.8)$ & $25.6(25.2-26.0)$ & $56.7(55.8-57.6)$ \\
\hline $45-54$ young boomers & $31.6(31.2-32.0)$ & $26.5(26.2-26.8)$ & $58.5(57.9-59.2)$ \\
\hline 55-64 old boomers & $32.3(31.9-32.7)$ & $27.1(26.8-27.3)$ & $59.9(59.4-60.5)$ \\
\hline $65-74$ silent generation & $33.8(33.3-34.2)$ & $28.0(27.7-28.4)$ & $62.1(61.3-62.8)$ \\
\hline 75-100 GI generation & $33.5(32.2-34.7)$ & $27.8(26.7-28.8)$ & $61.9(59.9-63.9)$ \\
\hline \multicolumn{4}{|l|}{ Gender } \\
\hline Male & $32.5(32.1-32.9)$ & $27.8(27.5-28.1)$ & $60.7(60.1-61.3)$ \\
\hline Female & $31.6(31.3-31.8)$ & $26.4(26.2-26.5)$ & $58.5(58.1-58.9)$ \\
\hline \multicolumn{4}{|l|}{ Health insurance } \\
\hline Yes & $32.1(31.9-32.3)$ & $26.9(26.7-27.0)$ & $59.5(59.1-59.8)$ \\
\hline No & $28.2(27.1-29.3)$ & $24.9(24.2-25.6)$ & $54.3(52.7-55.9)$ \\
\hline \multicolumn{4}{|l|}{ Education } \\
\hline High school or less & $30.8(30.2-31.4)$ & $26.2(25.8-26.6)$ & $57.9(56.9-58.8)$ \\
\hline College & $31.9(31.6-32.2)$ & $26.6(26.4-26.8)$ & $59.0(58.6-59.5)$ \\
\hline Advanced education & $32.7(32.3-33.1)$ & $27.7(27.4-28.0)$ & $60.7(60.1-61.4)$ \\
\hline \multicolumn{4}{|l|}{ Work status } \\
\hline Able to work & $32.0(31.7-32.3)$ & $27.1(26.9-27.3)$ & $59.7(59.3-60.1)$ \\
\hline Medically unable to work & $31.7(31.3-32.0)$ & $26.2(25.9-26.5)$ & $58.5(57.9-59.0)$ \\
\hline \multicolumn{4}{|l|}{ Primary condition } \\
\hline Fibromyalgia & $29.7(29.1-30.2)$ & $24.8(24.5-25.2)$ & $55.3(54.4-56.1)$ \\
\hline Multiple sclerosis & $33.1(32.7-33.5)$ & $27.8(27.5-28.1)$ & $60.3(60.7-61.9)$ \\
\hline Parkinson's disease & $33.5(32.9-34.1)$ & $28.0(27.5-8.5)$ & $61.8(60.9-62.7)$ \\
\hline Type 2 diabetes mellitus & $32.6(31.7-33.5)$ & $27.4(26.7-28.1)$ & $60.8(59.4-62.2)$ \\
\hline Epilepsy & $30.9(29.8-32.0)$ & $26.7(26.0-27.5)$ & $58.0(56.3-59.7)$ \\
\hline Bipolar disorder type 2 & $32.2(30.5-33.8)$ & $26.6(25.3-27.9)$ & $58.1(55.4-60.9)$ \\
\hline Rheumatoid arthritis & $32.3(31.1-33.5)$ & $26.9(26.1-27.7)$ & $59.5(57.7-61.3)$ \\
\hline Amyotrophic lateral sclerosis & $33.0(31.7-34.3)$ & $28.4(27.7-29.1)$ & $61.2(59.2-63.1)$ \\
\hline Systemic lupus erythematosus & $29.4(27.9-30.9)$ & $25.6(24.6-26.6)$ & $55.7(53.3-58.1)$ \\
\hline Major depressive disorder & $30.5(28.9-31.6)$ & $24.5(23.6-25.5)$ & $55.7(53.8-57.5)$ \\
\hline Idiopathic pulmonary fibrosis & $33.0(31.7-34.3)$ & $28.0(27.1-28.9)$ & $61.1(59.2-63.1)$ \\
\hline $\begin{array}{l}\text { Myalgic encephalomyelitis/ } \\
\text { chronic fatigue syndrome }\end{array}$ & $28.6(26.5-30.7)$ & $24.7(23.4-26.0)$ & $54.8(51.7-58.0)$ \\
\hline Migraine & $30.8(29.1-32.5)$ & $25.8(24.7-26.9)$ & $57.3(54.9-59.8)$ \\
\hline
\end{tabular}

Participants had the option of choosing not to respond to the survey questions. Scores are computed on all available data

Statistically significant difference $(p<0.05)$ is noted if the $95 \%$ CI between strata do not overlap. For example, the $95 \%$ CI for the total empowerment score ranges from 60.1 to 61.3 in males and from 58.1 to 58.9 in females. As the intervals do not overlap, the difference is statistically significant

EFA exploratory factor analysis, $C I$ confidence interval

medical decision making. It is not only provider relationships that are important in empowerment. Many participants in this study report enabling other patients and learning from others. Previous studies indicate that empowered patients demonstrate sensitivity to other patients and show a willingness to assist peers with similar problems [10]. However, even in this generally empowered group, there were concerns; sizable minorities of patients reported mismatches in their treatment goals compared with their providers' plans, insufficient time spent with providers during visits, and inadequate provider monitoring of ongoing care. This highlights the provider role in developing an empowering relationship in which the provider constructs a positive atmosphere by encouraging 
Fig. 2 Analysis of means with Nelson-Hsu adjustment analysis of empowerment scores by primary condition. Numbers indicate difference from the overall weighted sample mean. Statistical significance after Nelson-Hsu adjustment is denoted by an asterisk $(* * * p<0.001, * * p<0.01$, $* p<0.05$ )

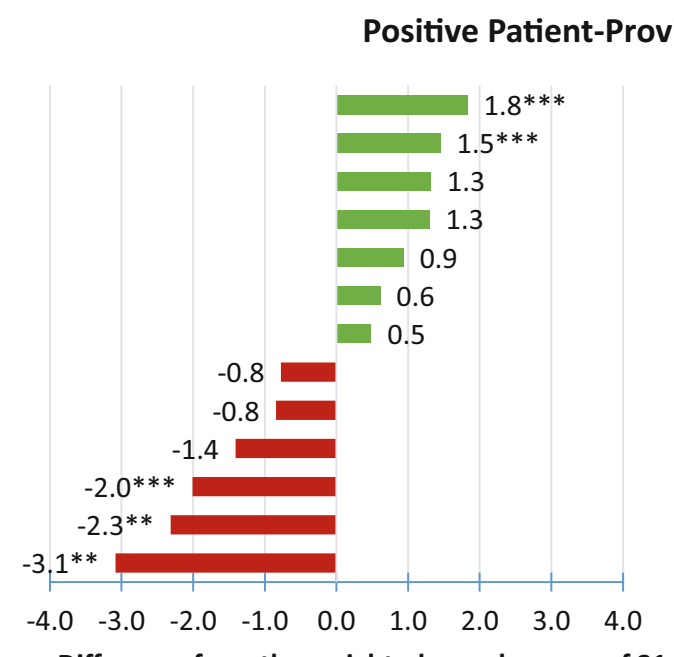

Difference from the weighted sample mean of 31.7
Parkinson's disease

Multiple sclerosis

Amyotrophic lateral sclerosis

Idiopathic pulmonary fibrosis

Diabetes Type 2

Rheumatoid arthritis

Bipolar Disorder, Type II

Epilepsy

Migraine

Major depressive disorder

Fibromyalgia

Systemic Lupus Erythematosus

Myalgic encephalomyelitis/Chronic fatigue...

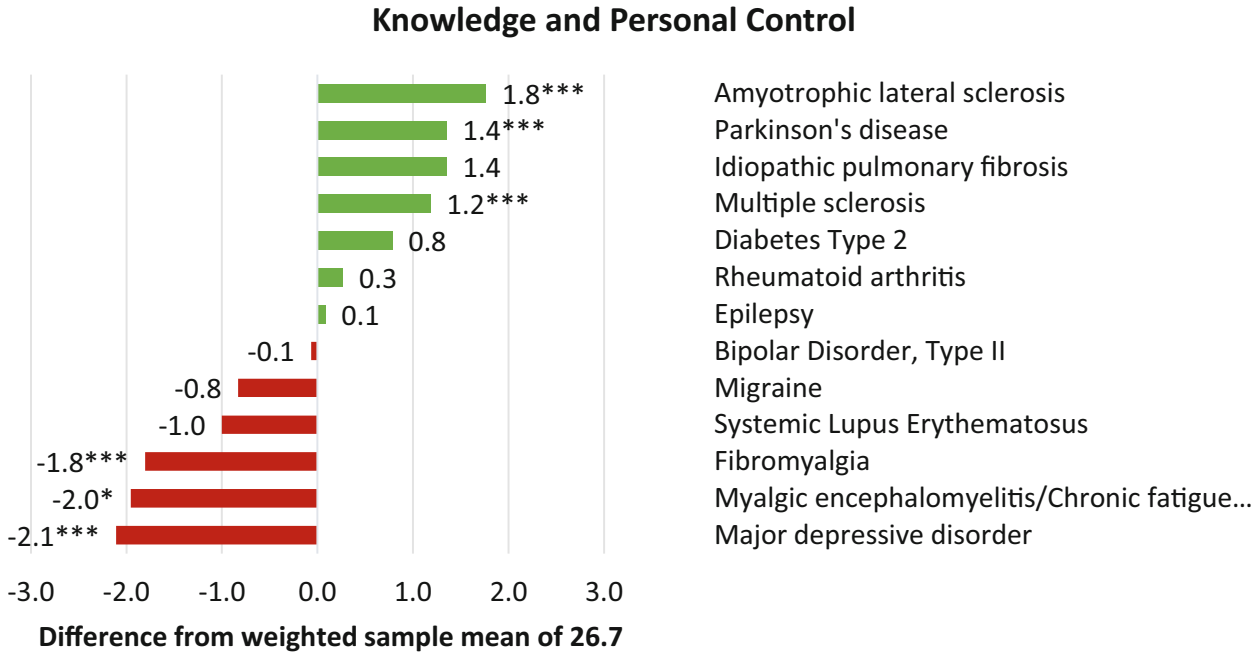

patients' emotional expression, offering individualized education, and allowing patients the time to make decisions [8].

\subsection{Empowerment Factors}

The patient and provider roles in empowerment were exemplified in the factors identified in this study-Positive Patient-Provider Interaction and Knowledge and Personal Control-which correspond to factors reported by Small et al. [10], i.e. 'knowledge and confidence in decision making' and 'positive attitude and sense of control'. The Positive Patient-Provider Interaction factor included items related to patient satisfaction, comprehension, and active involvement in treatment, and these have been associated with patient empowerment in previous studies [25]. Johnson et al. [12] identified two empowerment factors in HIVinfected patients-Informed, Committed, Collaborative, Engaged (ICCE), and Tolerance of Uncertainty (TU). The former subscale includes items associated with gaining knowledge and interacting with providers. Although the causality path is not clear from these data, it seems evident that empowerment includes a sense of self-efficacy in health information seeking, and a positive communication style between patients and providers [8].

The analysis of these empowerment factors yielded several key findings related to individual characteristics. Patients who are male, more educated, and insured evidenced greater levels of empowerment. Previous studies have found that men evidence higher empowerment levels than women [26]. A study of empowerment in diabetes patients also found a significant effect of gender where female patients may be struggling with greater psychological or family communication problems than males [27]. We also found that with increasing age, empowerment scores increased on both factors. Perhaps factors such as being male, older, and employed confer greater financial and social resources that enhance personal empowerment. 
Patients with myalgic encephalomyelitis/chronic fatigue syndrome and fibromyalgia scored lower on both factors compared with patients with amyotrophic lateral sclerosis, Parkinson's disease, and multiple sclerosis. The analysis of individual scale items in the Positive Patient-Provider Interaction factor indicated that the former groups of patients may feel less informed by their providers. With fibromyalgia and chronic fatigue syndrome, educational and self-management interventions that may enhance empowerment have been underutilized due to limited medical understanding, difficulties accessing qualified therapists, and lack of insurance coverage [28]. In addition, fibromyalgia and chronic fatigue syndrome may carry a stigma that detracts from empowerment as many of these patients perceive distrust and skepticism by their physicians with regard to their symptoms and clinical presentation [29]. Patients may face similar barriers in other stigmatized diseases such as mental health conditions [30], hepatitis C [31], and HIV [32]. The presence of stigma may lead to coping strategies that prevent empowerment, e.g. withdrawing from health providers or concealing information [33].

\subsection{Limitations}

There are several limitations worth noting. First, the EFA did not establish the factors within empowerment in a definitive manner. The purpose of this study was not to examine the dimensionality and psychometric properties of the items; hence, the EFA was purely exploratory. It is possible that some items that measure the constructs and domains of empowerment may not have been identified. Furthermore, given the cross-sectional design of the study, cause, effect or mediating pathways between the factors and improved patient outcomes could not be established. Additionally, because PLM is a real-world dataset, it possesses the limitations associated with such data, including self-selection and recall bias. It may represent the patient voice but the data are based on subjective self-reports, are derived from a convenience sample, and the mix of patients is representative of PLM and not necessarily of the medical population at large. No independent assessment of participants' health status was carried out. Finally, the PLM population skews toward a more educated, female population with chronic conditions, although this is typical for many health-oriented websites [34, 35]. In addition, this sample underrepresents the prevalent primary chronic diseases such as cardiometabolic diseases, so-called 'silent' diseases that may not lead people to join online social networks. One might reasonably expect that the issues highlighted in this paper may be more amplified in those with less financial resources, inadequate computer access, or limited knowledge of healthcare. However, this study may be more representative of chronic disease patients who are attuned to health issues or may be more engaged in their healthcare, an important subgroup that may help identify the issues that apply to the broader chronic disease population. Future surveys may benefit from strategies suggested by Dillman et al. [16], including email prompting, mixed methods (adding mail surveys), and the use of financial incentives to draw a broader chronic disease sample.

\subsection{Future Work}

Ultimately, such analyses may inform actionable steps that both providers and researchers can take in order to understand and improve patient empowerment. In terms of actionable steps for providers, several possibilities emerge from this data: (i) greater attention to achieving consensus with patients regarding treatment goal setting; (ii) provision of sufficient time to discuss patients' treatment needs during visits; (iii) promoting patients' health literacy to ensure that their informational needs have been met; and (iv) enhancing patients' sense of control in managing their disease through an understanding of disease warning signs/ symptoms, disease progression, and available treatment options. With certain groups, such as women and those with lesser education and health benefits, the provision of such strategies in an empowering atmosphere may be particularly critical.

Conditions that are difficult to diagnose and treat, or those that are stigmatized, may be linked to problematic interactions between provider and patient, and potentially associated with lower levels of empowerment. In diseases such as fibromyalgia, the psychosocial aspects of medical management become more essential, which may be due in part to providers' lack of training and knowledge in effective therapies that address these challenges [36]. Indeed, these patients expect more moral support from health professionals, while providers often need to address sources of frustration in treating difficult patients [37]. The use of advocacy and support groups may help bridge this gap. The creative use of evidence-based peer education programs can help advocates to engage and teach rudimentary empowerment skills to less empowered patients. The involvement of providers is important, especially in encouraging newly diagnosed patients to make contact and speak with advocacy groups.

In terms of future research, interpersonal and intrapersonal factors in empowerment have been identified but the causal relationships remain unclear [8]. Johnson postulates the role of personal resources, cultural/social/environmental factors, and intrapersonal factors as drivers of patient empowerment [9]. Further investigation of the most important outcome(s) is warranted. If empowerment can be 
considered an outcome, we envision further work to define it—as a set of positive health behaviors (e.g. self-management), enhanced clinical outcomes, or improved quality of life [8]. In addition, once an outcome is defined, it will be important to test the hypothesized multifactorial and mediating pathways of empowerment using causal models such as path analysis and structural equation modeling. Finally, research should address not only the types and severity of conditions but also differential disease characteristics that affect patient empowerment.

\section{Conclusions}

The goal of the present study was to gain an understanding of empowerment in terms of patient involvement with health information seeking, provider and peer interactions, and the access of healthcare. Even a fairly health-engaged chronic disease population can experience difficulties with aligning their goals with provider treatment goals and spending sufficient time with providers. This study identified two domains of empowerment that are consistent with previous studies. Empowerment levels differ across diseases, particularly those that are difficult to diagnose and treat, suggesting tailored disease-specific strategies to empower patients. Future work should address ways in which providers can overcome problematic interactions with patients, and research that can better define the relationship between empowerment domains and important clinical outcomes.

Acknowledgments Gabriel Eichler, Nancy-Lutz Paynter,Yeun Mi Yim, and Nikki Martin provided input into the study design and provided input during revision of the manuscript. Sonali Chopra provided input into the study design. Jessica Burton, Charlie Barr, Yeun Mi Yim, and Jenny Devenport assisted in the critical review of the analysis and methodology.

Author contributions Emil Chiauzzi assumed primary responsibility for writing the manuscript, and was involved in conceptualization of the study and survey. Pronabesh DasMahapatra participated in the design of the study and survey, planned and conducted the statistical analyses, and wrote the Methods and Results sections of the manuscript. Elisenda Cochin participated in study conceptualization and survey design and implementation, as well as production of the manuscript. Mikele Bunce, Raya Khoury, and Purav Dave assisted in data analysis and writing of the Results and Discussion sections, and provided expert input and review in the design of the survey and on the manuscript. The decision to submit for publication was made jointly.

\section{Compliance with Ethical Standards}

Funding This project was funded by Genentech, Inc.

Conflicts of interest Emil Chiauzzi, Pronabesh DasMahapatra, and Elisenda Cochin are employees of PatientsLikeMe and own stock/ options in PatientsLikeMe. The PatientsLikeMe Research and Developmentteam has received research support from Actelion, Amgen, AstraZeneca, Biogen, Boehringer Ingelheim, Celgene, Eisai, Genentech, Genzyme, Inflexxion, Janssen, Merck, Neuraltis, Novartis, Sanofi, and UCB. Mikele Bunce and Raya Khoury are employees of Genentech/Roche and own stock/options in Roche. Purav Dave is a former employee of Genentech and is currently a paid consultant for Genentech. Genentech (sponsor) employees participated in the design of the study, interpretation of the data, critical revision and approval of the manuscript, and the decision to submit the manuscript. The research protocol was approved by the NEIRB on 4 November 2014 and is in compliance with the ethical standards of the Declaration of Helsinki. Informed consent was obtained from all individual participants in the study.

Open Access This article is distributed under the terms of the Creative Commons Attribution-NonCommercial 4.0 International License (http://creativecommons.org/licenses/by-nc/4.0/), which permits any noncommercial use, distribution, and reproduction in any medium, provided you give appropriate credit to the original author(s) and the source, provide a link to the Creative Commons license, and indicate if changes were made.

\section{References}

1. HealthAffairs. Health policy brief: patient engagement. 2013. http://www.healthaffairs.org/healthpolicybriefs/brief.php?brief_ id=86. Accessed Feb 2015

2. Agency for Health Care Research and Quality. 2013 National health care disparities report. 2014. http://www.ahrq.gov/sites/ default/files/publications/files/2013nhdr.pdf. Accessed Dec 2015.

3. Institute of Medicine. Crossing the Quality Chasm. 2001. https:// www.iom.edu/ /media/Files/Report\%20Files/2001/Crossingthe-Quality-Chasm/Quality\%20Chasm\%202001\%20\%20report\% 20brief.pdf. Accessed Feb 2015

4. PCORI. Patient-empowering care management workgroup: topic brief. http://www.pcori.org/assets/2013/12/PCORI-Topic-BriefPatient-Empowering-Care-Management-Workgroup-120613.pdf. Accessed Aug 2015.

5. US FDA. The voice of the patient: lung cancer. 2013. http://www. fda.gov/downloads/ForIndustry/UserFees/PrescriptionDrugUser Fee/UCM379698.pdf. Accessed Aug 2015.

6. US Department of Health and Human Services. 2011 report to Congress: national strategy for quality improvement in health care. http://www.ahrq.gov/workingforquality/nqs/nqs2011 annlrpt. htm. Accessed Jan 2016.

7. Barello S, Graffigna G, Vegni E, Bosio AC. The challenges of conceptualizing patient engagement in health care: a lexicographic literature review. J Particip Med. 2014;6:e9.

8. Aujoulat I, d'Hoore W, Deccache A. Patient empowerment in theory and practice: polysemy or cacophony? Patient Educ Couns. 2007;66:13-20.

9. Johnson MO. The shifting landscape of health care: toward a model of health care empowerment. Am J Public Health. 2011;101:265-70.

10. Small N, Bower P, Chew-Graham CA, Whalley D, Protheroe J. Patient empowerment in long-term conditions: development and preliminary testing of a new measure. BMC Health Serv Res. 2013;13:263

11. Corrigan PW, Faber D, Rashid F, Leary M. The construct validity of empowerment among consumers of mental health services. Schizophr Res. 1999;38(1):77-84.

12. Johnson MO, Rose CD, Dilworth SE, Neilands TB. Advances in the conceptualization and measurement of health care 
empowerment: development and validation of the health care empowerment inventory. PLoS One. 2012;7(9):e45692.

13. Samoocha D, Bruinvels DJ, Elbers NA, Anema JR, van der Beek AJ. Effectiveness of web-based interventions on patient empowerment: a systematic review and meta-analysis. J Med Internet Res. 2010;12(2):e23.

14. Anderson RM, Funnell MM, Fitzgerald JT, Marrero DG. The Diabetes Empowerment Scale: a measure of psychosocial selfefficacy. Diabetes Care. 2000;23:739-43.

15. Brownstein CA, Brownstein JS, Williams DS III, Wicks P, Heywood JA. The power of social networking in medicine. Nat Biotechnol. 2009;27:888-90.

16. Dillman DA, Smyth JD, Christian LM. Internet, mail, and mixedmode surveys: the tailored design method. 3rd ed. New York: Wiley; 2009.

17. Eysenbach G. Improving the quality of web surveys: the checklist for reporting results of Internet E-Surveys (CHERRIES). J Med Internet Res. 2004;6(3):e34.

18. DiStefano C, Zhu M, Mîndrilă D. Understanding and using factor cores: considerations for the applied researcher. Pract Assess Res Eval. 2009;14:20.

19. Galesic M. Dropouts on the web: effects of interest and burden experienced during an online survey. J Off Stat. 2006;22:313-28.

20. Gerteis J, Izrael D, Deitz D, LeRoy L, Ricciardi R, Miller T, et al. Multiple chronic conditions chartbook: 2010 medical expenditure panel survey data. 2014. http://www.ahrq.gov/sites/default/files/ wysiwyg/professionals/prevention-chronic-care/decision $/ \mathrm{mcc} /$ mccchartbook.pdf. Accessed Dec 2015.

21. National Institute of Arthritis and Musculoskeletal and Skin Diseases. What is fibromyalgia? 2014. http://www.niams.nih.gov/ Health_Info/Fibromyalgia/fibromyalgia_ff.pdf. Accessed Dec 2015.

22. National Multiple Sclerosis Society. Who gets MS? (epidemiology). 2015. http://www.nationalmssociety.org/What-is-MS/WhoGets-MS. Accessed Dec 2015.

23. Dahodwala N, Siderowf A, Xie M, Noll E, Stern M, Mandell DS. Racial differences in the diagnosis of Parkinson's disease. Mov Disord. 2009;24(8):1200-5.

24. Cappelleri JC, Zou KH, Bushmakin AG, Alvir JMJ, Alemayehu D, Symonds T. Patient-reported outcomes: measurement, implementation and interpretation. Boca Raton: Chapman \& Hall/CRC Press; 2013.
25. Rohrer JE, Wilshusen L, Adamson SC, Merry S. Patient-centredness, self-rated health, and patient empowerment: should providers spend more time communicating with their patients? J Eval Clin Pract. 2008;14:548-51.

26. Tambuyzer E, Van Audenhove C. Is perceived patient involvement in mental health care associated with satisfaction and empowerment? Health Expect. 2015;18:516-26.

27. Hara Y, Iwashita S, Okada A, Tajiri Y, Nakayama H, Kato T, et al. Development of a novel, short, self-completed questionnaire on empowerment for patients with type 2 diabetes mellitus and an analysis of factors affecting patient empowerment. Biopsychosoc Med. 2014;8:19.

28. Williams DA, Kuper D, Segar M, Mohan N, Sheth M, Clauw DJ. Internet-enhanced management of fibromyalgia: a randomized controlled trial. Pain. 2010;151:694-702.

29. Institute of Medicine. Beyond myalgic encephalomyelitis/chronic fatigue syndrome: redefining an illness.2015. https://www.iom. edu/ /media/Files/Report\%20Files/2015/MECFS/MECFS_Report Brief.pdf. Accessed Dec 2015.

30. Corrigan P. How stigma interferes with mental health care. Am Psychol. 2004;59:614-25.

31. Marinho RT, Barreira DP. Hepatitis C, stigma and cure. World J Gastroenterol. 2013;19:6703-9.

32. French H, Greeff M, Watson M, Doak C. HIV stigma and disclosure experiences of people living with HIV in an urban and a rural setting. AIDS Care. 2015;27:1042-6.

33. Asbring $\mathrm{P}$, Narvanen AL. Women experienced chronic fatigue syndrome and fibromyalgia as stigmatizing. Evid Based Ment Health. 2002;5:127.

34. Kontos E, Blake KD, Chou WY, Prestin A. Predictors of ehealth usage: insights on the digital divide from the health information national trends survey 2012. J Med Internet Res. 2014;16:e172.

35. Thackeray R, Crookston BT, West JH. Correlates of health-related social media use among adults. J Med Internet Res. 2013;15(1):e21.

36. Hayes SM, Myhal GC, Thornton JF, Camerlain M, Jamison C, Cytryn $\mathrm{KN}$, et al. Fibromyalgia and the therapeutic relationship: where uncertainty meets attitude. Pain Res Manag. 2010;15(6):385-91.

37. Briones-Vozmediano E, Vives-Cases C, Ronda-Pérez E, GilGonzález D. Patients' and professionals' views on managing fibromyalgia. Pain Res Manag. 2013;18(1):19-24. 